\title{
ВЫРАЖЕНИЕ ДОЛЖЕНСТВОВАНИЯ В ОРИГИНАЛЕ РОМАНА Д. БРАУНА «ИНФЕРНО» И ЕГО ИСПАНСКОМ И РУССКОМ ПЕРЕВОДАХ
}

\section{EXPRESSION OF OBLIGATION IN THE ORIGINAL NOVEL "INFERNO" BY D. BROWN AND ITS SPANISH AND RUSSIAN TRANSLATIONS}

I. Ilina

Summary: This article discusses how to express the category of modality of duty, used in the text of the novel "Inferno" by D. Brown and its translations in Spanish and Russian. The category of modality of duty and obligation can have different connotations and be implemented using lexical, grammatical and syntactic means. A comparison of the linguistic means of expressing the obligation in the original novel and its translations led to the conclusion that the most commonly used modal verbs in the original novel are need to, have to, must, in the Spanish translation deber, tener que, in the Russian translation «быть должным», «нужно».

Keywords: modality, modality of duty, obligation, means of modality, translation.

\author{
Ильина Юлия Николаевна \\ К.фрилол.н., дочент, ФГБОУВО «Удмуртский \\ государственный университет», г. Ижевск \\ julianik23@mail.ru
}

Аннотация: В данной статье рассматриваются способы выражения категории модальности долженствования, используемые в тексте романа Д. Брауна «Инферно» и его переводах на испанском и русском языках. Категория модальности долженствования и вынужденности может иметь различные оттенки и реализовываться при помощи лексических, грамматических и синтаксических средств. Сравнение средств выражения долженствования в оригинале и переводах привело к выводу о том, что наиболее часто используемыми модальными глаголами в оригинале романа являются need to, have to, must, в испанском переводе - deber, tener que, в русском переводе «быть должным», «нужно».

Ключевые слова: модальность, модальность долженствования, вынужденность, средства модальности, перевод.
$\mathrm{M}$ одальность - понятийная категория со значением отношения говорящего к содержанию высказывания и отношения содержания высказывания к действительности, т.е. отношения сообщаемого к его реальному осуществлению [1, с. 246]. Известно, что модальность может содержать в себе значения утверждения, пожелания, приказания, достоверности, допущения, ирреальности и др.

Категория модальности необходимости и долженствования несет в себе различные оттенки значений: волюнтативности, побудительной желательности, необходимости совершить или, наоборот, не совершить действие, способности, умения, разрешения, запрета и т. д. Значение же долженствования характеризуется следующим: каузатор - веление долга; отношение субъекта действия к его реализации - нейтральное или положительное. Значение вынужденности обусловливается следующими признаками: вынужденное действие - это последствие воздействия чужой воли, чужого желания или обстоятельств; выполнение вынужденного действия негативно оценивается его субъектом. Модальность может выражаться лексическими средствами (модальными словами), лексико-грамматическими средствами (модальные глаголы), лексико-синтаксическими конструк- циями, модальными фразами с эпистемическими предикатами [2, с. 103, 164].

Среди средств, используемых в представленных в этой статье языках, можно назвать следующие: в английском языке это модальные глаголы и конструкции must, to have to, need, should, ought и др., в испанском языке следует упомянуть глаголы и структуры deber, tener que, haber de, necesitar, hacer falta и пр., в русском языке можно привести в пример глаголы и конструкции быть должным, быть обязанным, вынужденным, нужно, надо и т.д.

В данной статье рассматривается реализация категории модальности долженствования в художественном тексте, а именно в романе американского писателя Дэниэла Герхарда (Дэна) Брауна «Инферно», опубликованном в 2013 году, а также его переводов на испанском и русском языках. Роман представляет собой один из серии бестселлеров этого писателя о заговорах и тайных сообществах и связанных с ними приключениях главного героя произведения, профессора Роберта Лэнгдона. В этой книге герой оказывается во Флоренции и с ним происходит череда событий, которые могут повлечь за собой гибель человечества. Можно спорить о художе- 
ственной ценности данного произведения, однако отметим, что стремительно развивающийся сюжет данного романа обусловливает широкое использование различных средств для передачи именно этого смыслового посыла - понятие морального долга, тесно связанное с определениями чести и бесчестия. Кроме того, главный герой романа Роберт Лэнгдон на протяжении повествования неоднократно оказывается в ситуациях, где ему, согласно сложившимся обстоятельствам, приходится подчиняться воле других людей, что так же влияет на использование в романе исследуемых нами форм выражения долженствования.

В процессе чтения оригинала романа Д. Брауна на английском языке и его переводов на испанском, русском языках нами был произведен количественный подсчет и проведен анализ способов выражения долженствования, использованных в них [4]. В результате подсчетов можно представить следующую статистику: в оригинальной версии (на английском языке) автор использовал следующие конструкции:

- need to + infinitive 103 раза (36\%);

- to have to + infinitive 64 раза $(22.5 \%)$;

- should 61 раз (21.5\%);

- must 56 раз (20\%).

В переводе романа на испанском языке, переводом которого занималась Алеикс Монтото, мы установили, что были употреблены конструкции, приведенные ниже [5]:

- deber + infinitivo 143 раза (39.6\%);

- tener que + infinitivo 118 раз (32.7\%);

- deber de + infinitive 49 раз (13.7\%);

- necesitar + infinitivo/ que + sunjuntivo 30 раз (8.4\%);

- hacer falta + infinitivo 8 раз (2.2\%);

- ser necesario/ importante + infinitivo 7 раз (1.9\%);

- haber que + infinitivo 6 раз (1.6\%).

В переводе романа на русском языке коллектив переводчиков (В. Голышев, Л. Мотылев и В. Бабков) использовал следующие слова и конструкции для выражения долженствования [3]:

- быть должным что-то сделать 118 раз (47.8\%);

- нужно + инфинитив 54 раза (21.9\%);

- приходиться что-то делать 19 раз (7.7\%);

- следует + инфинитив 18 раз (7.3\%);

- надо + инфинитив 16 раз (6.5\%);

- необходимо + инфинитив 14 раз (5.6\%);

- предстоять 5 раз (2\%);

- быть обязанным что-то сделать 3 раза (1.2\%).

Далее рассмотрим каждый из приведенных выше глаголов и конструкций на английском языке и проанализируем выбор испанского и русского переводчиков.

Глагол need может быть как смысловым, так и модальным глаголом, и использоваться для выражения необхо- димости совершить действие со значением «нуждаться», «иметь надобность, потребность», «быть необходимым». Основное отличие от других глаголов долженствования заключается в том, что, употребляя need, мы подчеркиваем нашу зависимость, нужду в чем-либо. Рассмотрим примеры из текста романа (здесь и далее сначала представлены примеры на английском языке, а далее на испанском и русском языках).

Mr. Langdon, anxiety is common with brain injuries, but you need to keep your pulse rate down. No movement. No excitement. Just lie still and rest/ Señor Langdon, la ansiedad es común cuando se ha sufrido una lesión cerebral, pero debe mantener las pulsaciones bajas. No se mueva. No se excite. Quédese tumbado y descanse/ Мистер Лэнгдон, беспокойство - обычный симптом при мозговых травмах, но вам нельзя волноваться. Не двигайтесь. Надо сбить пульс. Просто лежите тихо и отдыхайте.

В данном примере глагол need является смысловым глаголом, имеет значение «нуждаться» (физическая необходимость), однако переводчик предложил в качестве эквивалента глагол deber, и фраза «уоu to keep your pulse rate down» переведена на испанский как «debe mantener las pulsaciones bajas» (дословно: «Вы должны поддерживать низкий пульс»), что видится нам не совсем корректным, т.к. речь идет в данной ситуации о физической необходимости выполнять действие, и более адекватным представляется в данном случае глагол necesitar. A в русском переводе эта фраза звучит как: «Надо сбить пульс», что кажется более адекватным в этом случае.

Модальная конструкция to have to + Infinitive используется в анализируемом нами произведении для передачи необходимости выполнения действия вследствие сложившихся условий, внешних обстоятельств. По значению эта конструкция очень схожа с конструкцией на испанском языке tener que + Infinitivo:

The entrance is way over at Pitti Palace. You'd have to drive through Porta Romana and go around/La entrada se encuentra en el Palazzo Pitti. Tendréis que ir por la Porta Romana/ Вход очень далеко, у двориа Питти. Для этого нужно nроехать через Римские ворота и обогнуть сзади.

В данном примере мы видим, что герои вследствие стечения обстоятельств и сложившихся условий вынуждены изменить свой маршрут не по собственной воле. Поэтому в переводе с английского на испанский язык конструкции to have to + Infinitive была адекватно использована конструкция tener que + Infinitivo. В переводе же на русском языке переводчик использовал «нужно», хотя адекватнее был бы следующий вариант: Вход очень далеко, у двориа Питти. Поэтому вам придется проехать через Римские ворота и обогнуть сзади. 
Рассмотрим другой пример с конструкциями have to, tener que в связке с инфинитивами:

- We have to call somebody. The consulate ... the police. Somebody/Tenemos que llamar a alguien. Al consulado, por ejemplo, a la policía, a alguien/ Мы должны позвонить кому-нибудь. Консульство ... полиция. Хотя бы кому-нибудь.

В этом случае, опять же, мы видим вынужденную ситуацию, вызванную стечением обстоятельств. Именно поэтому в переводах использованы эквивалентные структуры: в испанском tener que + Infinitivo, а в русском быть должным + инфинитив. В роли подлежащего в предложениях с данными конструкциями в романе «Инферно» выступают личные местоимения и существительные.

Модальный глагол should в английском языке имеет множество смысловых оттенков, в том числе выполняет функцию совета, рекомендации. В анализируемых нами примерах should также переводится на испанский язык посредством глагола deber, при этом в испанском языке используется форма условного наклонения этого глагола. Здесь этот модальный глагол имеет значение обязательства, но не такого строгого, как must, и обычно выражает долженствование в форме настойчивой рекомендации, то есть имеет значение «стоит», «стоило бы», это же значение имеет и форма debería в испанском языке. Тем не менее, в изученном материале переводчик на русский язык переводил такие предложения зачастую не с использованием конструкций со словами «следует», «стоит», а с «нужно», «должен»:

- I think you should rest a little bit, and maybe.../ Creo que debería descansar un poсо у quizá.../ Я думаю, Вам надо отдохнуть немного и, может быть...

Известно, что английский глагол must используется для обозначения строгих обязательств, которые нужно беспрекословно выполнить, при этом говорящий убежден в том, что это необходимо и правильно, а также для выражения приказа и принуждения. Наиболее часто, почти в 80\% случаев, английский модальный глагол must в произведении «Инферно» переводится на испанский язык при помощи глагола deber, и в 90\% случаев должен (быть должным) на русский язык. Конструкция deber + infinitivo чаще всего подразумевает чувство внутреннего обязательства, морального долга, острой, беспрекословной необходимости совершения действия. В данном значении глагол deber чаще всего употребляется с Presente de Indicativo, Pretérito Imperfecto de Indicativo, Condicional simple. Приведем примеры.

- There's something important I must show you before we call anyone/ Hay algo importante que debo enseñarte antes de que llamemos a nadie/ Ecmь кое-то важное, что я должен показать тебе прежде, чем мы позвоним кому-нибудь.
- I have no recollection of meeting her, but every time I see her face, I have an overwhelming sense that I must help her/ No lo sé, no recuerdo haberla conocido, pero cada vez que veo su rostro, tengo la abrumadora sensación de que debo ayudarla/ Я не знаю, я не помню, чтобы встречал ее, но каждый раз, когда я вижу ее лицо, у меня возникает непреодолимое чувство, что я должен помочь ей.

Глагол must употребляется в приведенных примерах для выражения необходимости совершения действия, при этом человек верит в то, что это действие нужно обязательно выполнить. В отличие от глагола have to модальный глагол must, как и в испанском языке глагол deber, скорее означает осознанную самим говорящим необходимость, исходящую изнутри, а не вызванную по принуждению внешними обстоятельствами:

- I know what I must do/Sé lo que debo hacer/ Я знаю, что я должен делать.

- For the love of Mankind, I must protect my masterpiecel Por amor a la humanidad, debo proteger mi obra maestra/ Из любви к Человечеству я должен защитить свой шедевр.

- Также в романе глагол must встречается в значении настоятельного совета или даже приказа:

- "The gift should not be delivered too soon. You must keep it hidden until ..." He paused, suddenly lost in thought/ "El regalo no debe ser entregado antes de tiempo. Debe permanecer oculto hasta..." Se quedó callado y se sumió en sus pensamientos/"Эmom noдaрок не следует доставлять преждевременно. Вы должны держать его в тайне до тех пор, пока..." Он остановился, внезапно подумав о чём-то.

Также необходимо упомянуть, что при подсчете средств выражения долженствования в романе на русском языке мы столкнулись с тем, что переводчик использовал множество модальных слов и конструкций, выражающих долженствование: предстоять, приходиться, полагаться, быть обязанным что-то сделать и т.д. Например:

- "Before we meet Satan," Langdon declared, his deep voice resonating over the loudspeakers, "we must pass through the ten ditches of the Malebolge, in which are punished the fraudulent - those guilty of deliberate evil."I - Hemos descendido los nueve círculos del infierno hasta el centro de la Tierra - su voz resonó por los altavoces - y nos hemos encontrado cara a cara con el mismísimo Satán/ - Прежде, чем мы дойдём до Сатаны, - объявил Лэнгдон; голос его эхом отзывался в динамиках, - нам предстоum пройти через десять Рвов пороков, в которых наказывают мошенников - тех, кто повинен в высвобождении зла.

Отметим, что в данном примере в испанском пере- 
воде также отсутствуют явные показатели выражения долженствования. Дословно это переводилось бы так: Мы прошли через девять кругов ада до чентра Земли его голос отразился в динамиках —, и мы встретились лицом к лицу с самим Сатаной. Переводчик использовал законченное прошедшее время Pretérito Perfecto de Indicativo для того, чтобы показать, что действие обязательно будет совершено в будущем (в это время Лэнгдон показывает на карте свои действия).

Подводя итоги, следует отметить, что категория модальности - одна из самых противоречивых в языке. Существует множество определений этой категории, основными способами выражения которой в речи являются модальные глаголы, формы наклонения, интонация и модальные слова. В свою же очередь, модальные слова - разряд неизменяемых слов, служащих для выражения отношения говорящего к содержанию высказывания. Модальные глаголы - глаголы, выражающие не действие, а отношение к нему: возможность, необходимость, способность, вероятность и т. д. совершения действия, выраженного инфинитивом смыслового глагола, следующего за модальным.

Наиболее часто употребляемыми средствами выражения долженствования в данном романе являются модальные глаголы англ. need to, have to, must; исп. deber, tener que и рус. быть должным, нужно с инфинитивом. На примере данного художественного текста можно сделать вывод, что модальные глаголы и конструкции играют неоценимую роль в передаче оттенков отношения говорящего к действительности. Благодаря использованию модальных глаголов и конструкций, выражающих долженствование, в своем произведении автор добился наиболее точного отображения характера и поведения героев, культурных и социальных норм, а переводчики постарались найти наиболее подходящие с их точки зрения эквиваленты.

\section{ЛИТЕРАТУРА}

1. Ахманова 0.С. Словарь лингвистических терминов. - М.: Советская энциклопедия, 1986. - 448 с.

2. Беляева М.А. Грамматика английского языка. - М.: Высшая школа, 1989. - 259 с.

3. Браун Д. Инферно. М.: АСТ, 2013. - 544 с.

4. Brown D. Inferno. Bantam press, 2013. - $454 \mathrm{p}$.

5. Brown D. Inferno. Barcelona: Editorial Planeta, S.A., 2013. - 551 p.

○ Ильина Юлия Николаевна (julianik23@mail.ru). 